\title{
Acute Response of Heart Rate of Pregnant Women to Aerobic Dance Exercise
}

\author{
Jovita A. Daniel1 ${ }^{*}$, Sandra C. Okoli², Edith I. Mbakwe², Anthonia A. Udoaku², Emily A. Nzeribe ${ }^{3}$ \\ ${ }^{1}$ Department of Prosthetics and Orthotics, School of Health Science Technology, Federal University of Technology, Owerri, \\ Nigeria \\ ${ }^{2}$ Department of Physiotherapy, Federal Medical Centre, Owerri, Nigeria \\ ${ }^{3}$ Department of Obstetrics and Gynecology, Federal Medical Centre, Owerri, Nigeria \\ Email: *dchrisjovy@yahoo.com
}

How to cite this paper: Daniel, J.A., Okoli, S.C., Mbakwe, E.I., Udoaku, A.A. and Nzeribe, E.A. (2021) Acute Response of Heart Rate of Pregnant Women to Aerobic Dance Exercise. Journal of Biosciences and Medicines, 9, 117-123.

https://doi.org/10.4236/jbm.2021.910010

Received: September 7, 2021

Accepted: October 18, 2021

Published: October 21, 2021

Copyright (c) 2021 by author(s) and Scientific Research Publishing Inc. This work is licensed under the Creative Commons Attribution International License (CC BY 4.0) http://creativecommons.org/licenses/by/4.0/

\begin{abstract}
This was a Pre-test/Post-test research designed to study the acute heart rate response of pregnant women to aerobic dance exercise. Twenty four (24) pregnant women with no complications participated in this study. HR increased significantly after 30 minutes exercise [7.292, $\mathrm{P}=0.004(\mathrm{P}<0.05)]$ and then decreased significantly again after 30 minutes rest, post exercise $[10.00, P=0.0001(P<0.05)]$. The heart rate normalised after 30 minutes rest, showing no significant difference from the pre-exercise value $[2.708, \mathrm{P}=$ $0.517(\mathrm{P}>0.05)]$. Moderate intensity Aerobic Dance Exercise may not precipitate adverse acute cardiorespiratory response in pregnant women with no complications.
\end{abstract}

\section{Keywords}

Aerobic Dance, Heart Rate, Exercise, Pregnancy

\section{Introduction}

With the increase in acceptability of exercise in pregnancy among pregnant women and their attending Physicians, the need to ascertain the safety of most of the commonly recommended exercises for the mother and fetus becomes more important. The normal development of a fetus depends wholly on the mother [1] and maternal actions and inactions may affect the fetus positively or negatively. During exercise, blood flow is redistributed to the muscles. The reduced flow to the visceral organs may compromise the uterine blood flow because the fetus requires a continuous and adequate supply of oxygen and nutrients for its metabolism, growth and waste product removal [2]. Severe and 
acute interference with the supply of blood flow is likely to cause hypoxic damage, whereas milder, more chronic reductions may result in suboptimal growth [3]. Concerns about the effects of exercise on the uterine environment and the fetus have been voiced by many physicians [4]. In particular, studies centred around the shift of blood from the splanchnic area to the skeletal muscles of pregnant women after a bout of exercise and the possible effects of this on the fetus [5] [6]. Fears were dispelled by tests that showed that there was not only rapid reversal but a compensatory "flush-back", with an increase in uterine blood flow after cessation of exercise [7]. Monitoring of the fetal heart in response to maternal exercise showed rates within normal limits and return to baseline within 30 minutes [8] [9] [10] [11].

Exercise has been used in rehabilitative medicine as a safe, non-pharmacologic treatment for people of various ages for reasons including, but not limited to, obesity, osteoarthritis, aging, musculoskeletal problems in children, athletes with disabilities, and pregnancy [12]. Some researchers have postulated that exercise during pregnancy is safe and beneficial for the mother, fetus, and child and pose no risks [13]-[18], so long as the exercises are performed within the stipulated guidelines by American College of Obstetrics and Gynaecology (ACOG) [19]. Maternal exercise during pregnancy can improve cardiovascular function in women during pregnancy without adverse effects on fetal growth [15] [16] [17]. For example, research has shown that pregnant women who exercise have a lower HR at rest and during exercise, increased stroke volume, and increased oxygen uptake [15] [16]. Additionally, fetuses of women who exercise demonstrate advanced gestational age related to a lower fetal HR [15] [16].

Aerobic dance is one of the exercises assumed to be very safe for pregnant women and so is about one of the most recommended exercise regimen by healthcare provider during antenatal health talk. This study monitored the acute cardiorespiratory response of pregnant women to aerobic dance exercise and recovery time of same women after termination of the exercise.

\section{Methods}

Study Design and Subjects: This is a pretest/posttest study conducted in a Federal Government Hospital in the South Eastern part of Nigeria, where a total of 33 pregnant women attending antenatal clinic at the facility indicated interest to participate in the study. The subjects volunteered to participate without any form of inducement or persuasion. They were screened for any of the conditions contraindicating participation in antenatal exercises as stipulated in ACOG [19]. Screening was carried out using Physical Activity Readiness Medical Examination [20]. Twenty nine (29) of them met the inclusion criteria and were recruited for the study. They were required to read and sign informed consent form after being adequately informed of the purpose and procedure of the study. Only women who were pregnant and not less than 16 weeks of gestation were allowed to participate in this study. Both primaparous and multiparous mothers were al- 
lowed to participate in the study. None of the subjects was previously involved in any form of exercise programme as that was one of the inclusion criteria.

Pulse Rate (PR) of participants was measure and documented prior to commencement of exercise programme using NZ 009 Arm Automatic blood pressure monitor, after 10 minutes rest in upright sitting position. Participants were put through a warm up exercise in form of low intensity aerobic dance to a beat of a slow music. The warm up exercise was maintained at intensity of 11 to 12 on Borg Scale of Perceived Exertion [21]. After 10 minutes warm up, the music was changed to a faster track of a pre-recorded beat that made the women dance at an intensity 13 to 14 on the Borg Scale of perceived exertion. They sang along as they danced, as a familiar music tone was used. The participants danced for 20 minutes and then, the music was switched back to the slow music as cool down for 5 minutes.

The PR was taken again and documented at the end of the 30 minutes dance exercise. Participants were allowed to rest for 30 minutes and then the final reading of their blood pressure and pulse rate were taken. All statistical analyses were performed on IBM compatible microcomputer, using the statistical package for social science (SPSS) (window version 17.0 Chigaco IL, USA). The probability level was set at 0.05 . The report on the blood pressure response was reported in another publication by the authors [22].

\section{Results}

Five (5) of the women could not complete the study as they could not participate in the aerobic dance to the end of the 30 minutes and so their data were not included in the analysis as their data were incomplete. Data from 24 participants who completed the 30 minutes exercise programme were analysed. One way Repeated ANOVA was employed to analyse the data. Descriptive statistics of Means and Standard Deviation were computed and presented in this article.

Our finding showed good recovery of the maternal heart rate after 30 minutes of rest following the aerobic dance exercise. There was an initial significant increase in the maternal heart rate with a mean increase of 7.29, $\mathrm{P}=0.004(\mathrm{P}<$ $0.05)$ after the exercise. After 30 minutes rest, the heart rate returned to normal with a mean decrease of $10.00, \mathrm{P}=0.0001(\mathrm{P}<0.05)$ from the exercised value.

Table 1 shows information regarding to the demographic characteristics of the participants. The information shown are; maternal age, height, weight, BMI, gestational age.

As shown in Table 2, the mean pulse rate (PR) increased from $92.71 \pm 12.14$ $\mathrm{b} / \mathrm{m}$ pre-exercise to $100.00 \pm 13.38$ beats per min after 30 minutes exercise and then reduced to $90.00 \pm 9.97$ beats per min after 30 minutes post-exercise rest.

Assumption of sphericity as tested by Mauchly's test of sphericity was violated (Table 3), $\mathrm{X}^{2}(2)=6.910, \mathrm{P}=0.032$. Epsilon $(\Sigma)$ was 0.648 , as calculated according to Greenhouse \& Geisser (1959) and was used to correct the one-way repeated ANOVA. Pulse rate mean was statistically significantly different at the different points of measurement, $\mathrm{F}(1.575,36.233)=17.791, \mathrm{P}<0.0005$ (Table 4). 
Table 1. Demographic information of participants.

\begin{tabular}{lccccc}
\hline & Minimum & Maximum & Mean & Std. Deviation & $\mathrm{N}$ \\
\hline Maternal Age & 20 & 36 & 28.67 & 3.50 & 24 \\
Gestational age (weeks) & 17 & 40 & 29.88 & 5.77 & 24 \\
Pregnancy Body Mass Index (BMI) & 20.0 & 45.0 & 29.19 & 5.86 & 24 \\
Maternal Weight & 55.00 & 121.00 & 80.21 & 16.08 & 24 \\
Maternal Height & 1.54 & 1.92 & 1.66 & 0.08 & 24 \\
\hline
\end{tabular}

Table 2. Descriptive statistics of pulse rate (PR).

\begin{tabular}{lccc}
\hline & Mean & Std. Deviation & N \\
\hline Pre-exercise PR & 92.71 & 12.139 & 24 \\
Within Exercise After 30 mins Exercise & 100.00 & 13.381 & 24 \\
30 mins post-exercise rest & 90.00 & 9.974 & 24 \\
\hline
\end{tabular}

Table 3. One-way repeated ANOVA of the PR.

\begin{tabular}{lccccc}
\hline \multicolumn{1}{c}{ Source } & SS & df & MS & F & Sig. \\
\hline Sphericity Assumed & 1284.028 & 2 & 815.070 & 17.791 & 0.001 \\
Error & 1659.972 & 46 & & & \\
\hline
\end{tabular}

Table 4. Bonferroni post-hoc test for the PR.

\begin{tabular}{|c|c|c|c|c|c|c|}
\hline \multirow{2}{*}{ I } & \multirow{2}{*}{$\mathrm{J}$} & \multirow{2}{*}{$\begin{array}{c}\text { Mean Difference } \\
(\mathrm{I}-\mathrm{J})\end{array}$} & \multirow{2}{*}{ Std. Error } & \multirow{2}{*}{ Sig. } & \multicolumn{2}{|c|}{$95 \%$ CI } \\
\hline & & & & & Lower bond & Upper bond \\
\hline \multirow{2}{*}{1} & 2 & -7.292 & 1.968 & 0.004 & -12.374 & -2.209 \\
\hline & 3 & 2.708 & 1.923 & 0.517 & -2.257 & 7.673 \\
\hline \multirow{2}{*}{2} & 1 & 7.292 & 1.968 & 0.004 & 2.209 & 12.374 \\
\hline & 3 & 10.000 & 1.204 & 0.000 & 6.892 & 13.108 \\
\hline \multirow{2}{*}{3} & 1 & -2.708 & 1.923 & 0.517 & -7.673 & 2.257 \\
\hline & 2 & -10.000 & 1.204 & 0.000 & -13.108 & -6.892 \\
\hline
\end{tabular}

As shown in Table 4, there was statistically significant difference in the mean $\mathrm{PR}$ from pre-exercise to 30 minutes exercise with increase of 7.29, $\mathrm{P}=0.004(\mathrm{P}<$ 0.05). There was also statistically significant difference in the PR from after 30 minutes exercise to after 30 minutes post-exercise rest with a decrease of $10.00, \mathrm{P}$ $=0.0001(\mathrm{P}<0.05)$. However, there was no statistically significant difference between the $\mathrm{PR}$ of the women at the pre-exercise and after 30 minutes post-exercise rest. The difference being 2.708, $\mathrm{P}=0.517(\mathrm{P}>0.05)$.

\section{Discussion and Conclusion}

The aim of this study was to determine the acute maternal heart rate response to a single session of aerobic dance exercise in pregnant women without any complication. This was meant to give an insight into the possible risk that could arise 
from participating in exercise programme by pregnant women as Heart rate response is one of the parameters used to determine the safety of an exercise programme. The result shows that the women recovered to their resting HR values after 30 minutes rest, suggesting that the moderate intensity exercise (aerobic dance) may not pose any cardiorespiratory risk on the women but rather, may be associated with positive effects. Our finding can serve as a basis for further studies as there are no studies on the acute maternal heart rate response to exercise, rather studies were mostly on fetal heart rate variability [23] [24]. Our finding is in corroboration with the findings of some researchers who studied the effect of exercise on maternal and fetal HR, though they mostly studied effect of exercise performed for a longer period of time, unlike our study that looked at acute effect of just a bout of exercise session on the pregnant women's heart rate.

Perales et al. [25] recorded good recovery pattern in the mothers following exercise sessions. Other studies on foetal heart rate showed good responses of the foetal hearts to maternal exercise workout. Our study concentrated on the heart rate response of the mothers, believed to be very important because the effect on the women will determine the safety of the exercise programme on their foetuses.

Following the timely recovery of the maternal heart rate observed from our study, the aerobic dance exercise could be said to be safe for the women and their unborn babies as it did not precipitate any untoward cardiorespiratory response on the women.

It is therefore recommended that pregnant women in their $2^{\text {nd }}$ trimester and above, who have no complications or conditions contraindicating exercising in pregnancy should be encouraged to participate in these exercises to gain the benefits associated with exercising in pregnancy.

\section{Acknowledgements}

We thank the pregnant women for participating in this study. We also thank the management of the Federal Medical Centre, where this study was conducted for approving antenatal exercise programme in the hospital which is run by the Physiotherapy Department of the hospital.

\section{Declarations}

There was no funding for this research work.

\section{Conflicts of Interest}

The authors declare no conflict of interest.

\section{References}

[1] Gorski, J. (1985) Exercise during Pregnancy: Maternal and Fetal Responses. A Brief Review. Medicine \& Science in Sports \& Exercise, 17, 407-416. https://doi.org/10.1249/00005768-198508000-00001 
[2] Wolfe, L.A., Brenner, I.K. and Mottola, M.F. (1994) Maternal Exercise, Fetal Well-Being and Pregnancy Outcome. Exercise and Sport Sciences Reviews, 22, 145-194. https://doi.org/10.1249/00003677-199401000-00008

[3] Lotgering, F.K., Gilbert, R.D. and Longo, L.D. (1985) Maternal and Fetal Responses to Exercise during Pregnancy. Physiological Reviews, 65, 1-36. https://doi.org/10.1152/physrev.1985.65.1.1

[4] Shrock, P. (2008) Exercise and Physical Activity during Pregnancy. Global Library of Women's Medicine.

[5] Dale, E. and Mullinax, K. (1988) Physiological Adaptations and Considerations of Exercise during Pregnancy. In: Wilder, E., Ed., Obstetrics and Gynecology Physical Therapy, Churchill Livingstone, New York.

[6] Drinkwater, B. and Artal, R. (1991) Heat Stress and Pregnancy. In: Mittlemark, R. and Drinkwater, B., Eds., Exercise in Pregnancy, Williams and Wilkins, Baltimore, 199.

[7] Balaskas, J. and Balaskas, A. (1979) New Life: Exercises for Pregnancy and Childbirth. Sidwick and Jackson, London.

[8] Clapp, J., Little, K. and Capress, E. (1993) Fetal Heart Rate Response to Sustained Recreational Exercise. American Journal of Obstetrics \& Gynecology, 168, 198-206. https://doi.org/10.1016/S0002-9378(12)90914-X

[9] Shangold, M. (1985) Complete Sports Medicine Book for Women. Simon and Shuster, New York.

[10] Rice, P. and Fort, I. (1991) Relationship of Maternal Exercise on Labor, Delivery and Health of Newborn. The Journal of Sports Medicine and Physical Fitness, 31, 95-99.

[11] Carpenter, M., Sady, S., Sady, M., Haydon, B., Coustan, D. and Thompson, P. (1990) Effects of Maternal Weight Gain during Pregnancy on Exercise Performance. Journal of Applied Physiology (1985), 68, 1173-1176. https://doi.org/10.1152/jappl.1990.68.3.1173

[12] Willick, S., Akau, C.K., Harrast, M.A., et al. (2009) Sports and Performing Arts Medicine: 5. Special Populations. PM\&R, 1, S78-S82.

https://doi.org/10.1016/j.pmrj.2009.01.023

[13] Veille, J.C. (1996) Maternal and Fetal Cardiovascular Response to Exercise during Pregnancy. Seminars in Perinatology, 20, 250-262. https://doi.org/10.1016/S0146-0005(96)80018-8

[14] Wolfe, L.A., Preston, R.J., Burggraf, G.W., et al. (1999) Effects of Pregnancy and Chronic Exercise on Maternal Cardiac Structure and Function. Canadian Journal of Physiology and Pharmacology, 77, 909-917. https://doi.org/10.1139/y99-093

[15] Prather, H., Spitznagle, T. and Hunt, D. (2012) Benefits of Exercise during Pregnancy. $P M R, 4,845-850$. https://doi.org/10.1016/j.pmrj.2012.07.012

[16] Kalisiak, B. and Spitznagle, T. (2009) What Effect Does an Exercise Program for Healthy Pregnant Women Have on the Mother, Fetus, and Child? PMR, 1, 261-266. https://doi.org/10.1016/j.pmrj.2008.12.006

[17] Wolfe, L.A. and Davies, G.A. (2003) Canadian Guidelines for Exercise in Pregnancy. Clinical Obstetrics and Gynecology, 46, 488-495. https://doi.org/10.1097/00003081-200306000-00027

[18] Daniel, J.A., Ezeugwu, C.C. and Nwaogu, E.I. (2015) Effects of Antenatal Exercise on Length of Gestation among Women Attending Antenatal Clinic of the Federal Medical Centre Owerri, Southeast Nigeria. International Journal of Health and Re- 
habilitation Sciences, 4, 212-217. https://doi.org/10.5455/ijhrs.000000091

[19] Artal, R. and O’Toole, M. (2003) Exercise in Pregnancy: Guidelines of the American College of Obstetricians and Gynecologists for Exercise during Pregnancy and the Postpartum Period. British Journal of Sports Medicine, 37, 6-12.

https://doi.org/10.1136/bjsm.37.1.6

[20] Canadian Society for Exercise Physiology, 2015. https://www.chp.gov.hk>files

[21] Borg, G. (1998) Borg's Perceived Exertion and Pain Scales. Human Kinetics Publishers, 51.

[22] Daniel, J.A., Nwaogu, E.I., Okoli, S.C. and Nzeribe, E.A. (2019) Acute Effect of Aerobic Dance Exercise on Blood Pressure of Normotensive Pregnant Nigerian Women. International Research Journal of Medicine and Medical Sciences, 7, 28-33. https://doi.org/10.30918/IRJMMS.71.19.013

[23] May, L.E., Knowlton, J., Hanson, J., Suminski, R., et al. (2016) Effects of Exercise during Pregnancy on Maternal Heart Rate and Heart Rate Variability. PMR Journals, 8, 611-617. https://doi.org/10.1016/j.pmrj.2015.11.006

[24] Papp, M.E., Linfors, P., Storck, N. and Wandell, P.E. (2013) Increased Heart Rate Variability But No Effect on Blood Pressure from 8 Weeks of Hatha Yoga-A Pilot Study. BMC Research Notes, 6, 59. https://doi.org/10.1186/1756-0500-6-59

[25] Perales, M., Mateos, S., Vargas, M., et al. (2015) Fetal and Maternal Heart Rate Responses to Exercise in Pregnant Women. A Randomized Controlled Trial. Archivos de Medicina del Deporte, 32, 361-367. 